
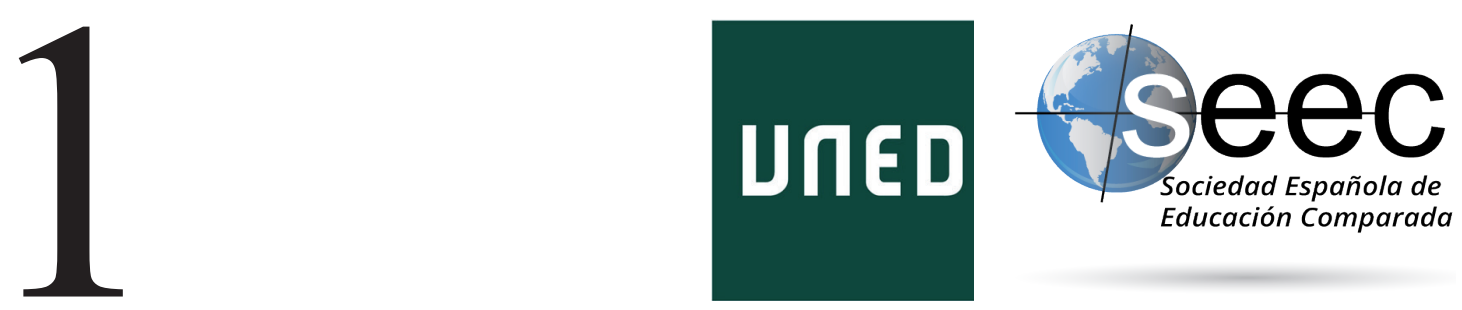

\title{
Biopolíticas de cierre de centros educativos desde una perspectiva de género: los casos de España y Suecia
}

Biopolitics of educative centers closing from gender equality perspective: the cases of Spain and Sweden

\section{Cristina Pulido-Montes*; \\ Guadalupe Francia**; Ana Ancheta-Arrabal***}

DoI: $10.5944 /$ reec.38.2021.29021

\section{Recibido: 1 de diciembre de 2020 Aceptado: 16 de marzo de 2021}

\footnotetext{
* Cristina Pulido-Montes: Universidad de Valencia. Departamento de Educación Comparada e Historia de la Educación. Datos de contacto: E-mail: cristina.pulido@uv.es. OrcID: https://orcid.org/oooo-00o31087-461X

** Guadalupe Francia: University of Gavle. Sweden. Facultad de Educación y Ciencias Empresariales, Profesora de Educación. Datos de contacto: E-mail: guadalupe.francia@hig.se. Orcid: https://orcid. org/0000-0002-3539-3022

***Ana Ancheta-Arrabal: Universidad de Valencia. Departamento de Educación Comparada e Historia de la Educación, Profesora Contratada-Doctor. Datos de contacto: E-mail: ana.ancheta@uv.es. OrciD: https:// orcid.org/0ooo-0002-9833-242X
} 


\title{
Resumen
}

Una de las medidas políticas para hacer frente a la pandemia Covid-19 de especial interés por su amplio alcance global y por sus implicaciones en la desigualdad de género es el cierre de centros educativos. Partiendo desde una perspectiva de género, este trabajo analiza las políticas de cierre de centros educativos como estrategias políticas de respuesta y prevención a la pandemia Covid-19 en España y Suecia. Teniendo como base del marco teórico la concepción de biopolítica de Didier Fassin articulada con el concepto performativo de género de Judith Butler, se analizan: estadísticas nacionales, informes gubernamentales y políticas educativas durante el período marzo-noviembre de 2020 en ambos países. Esta investigación muestra que a pesar de que la toma de decisiones con relación al cierre de escuelas cómo medida de contención ha sido desarrollada desde modelos diferenciados, los efectos en el contagio y mortalidad poblacional han sido similares en ambos escenarios. En ambos casos las medidas de cierre de centros educativos han contribuido a la profundización de desigualdades de género ya existentes en cada sociedad. El estudio demuestra la necesidad de desarrollar estudios sobre el cierre de centros educativos cómo estrategia de control de la pandemia desde una perspectiva de género intersectorial.

Palabras clave: igualdad de género; cierre de centros educativos; modelos de bienestar; Covid-19; biopolítica

\begin{abstract}
One of the political measures to deal with the Covid-19 pandemic of special interest due to its broad global reach and its implications for gender inequality is the closure of educational centers. From a gender perspective basis, this work analyzes the policies for the closure of educational centers as political strategies for response and prevention to the Covid-19 pandemic in Spain and Sweden. Based on Didier Fassin's conception of biopolitics articulated with Judith Butler's performative concept of gender as theoretical starting point, this research analyzed national statistics, government reports, and educational policies during the March-November 2020 period in both countries. This research shows that, despite the differences of the two selected national models, the educational centers closures has resulted in similar effects on contagion and population mortality. In both cases, the closure has contributed to the deepening of already existing gender inequalities in each society. The study demonstrates the need to develop studies on the closure of educational centers as a strategy to control the pandemic from an intersectional gender perspective.
\end{abstract}

Keywords: gender equality; educative centers closure; welfare models; Covid-19; biopolitics. 


\section{Introducción.}

La pandemia causada por el virus Covid-19 ha profundizado las desigualdades de género, tanto en los contextos locales, como globales. Diversos organismos internacionales han dado la voz de alarma sobre el aumento en tiempos de Covid-19 de la violencia contra las mujeres y niñas, de la responsabilidad de las mujeres sobre los cuidados y las tareas domésticas no remuneradas ante el cierre de escuelas y lugares de trabajo, así como sobre la necesidad urgente de una mayor atención hacia las mujeres en los adultos de la tercera edad y enfermos de Covid-19 (European Institute for Gender Equality, EIGE, 2020; PNUD, 2020; ONU-MUJERES, 2020). El reconocimiento de estas desigualdades de género es un paso fundamental para comprender los efectos de esta emergencia sanitaria y para crear políticas basadas en intervenciones efectivas y equitativas.

Una de las medidas políticas para hacer frente a la pandemia de la Covid-19 de especial interés para profundizar en el estudio de las desigualdades de género son las políticas de cierre de centros educativos. Este análisis viene motivado, entre otras razones, por el alcance que tuvo el cierre de los centros educativos en el nivel global llegando a afectar al 70 \% de la población estudiantil mundial en los primeros meses de la pandemia según datos de la UNESCO (2020).

Partiendo de una perspectiva de género, este trabajo tiene por objetivo analizar las políticas educativas de cierre de centros educativos como estrategias biopolíticas de respuesta y prevención de la pandemia Covid-19 en España y Suecia y su repercusión en la igualdad de género de ambas sociedades.

Los conceptos de biopolítica de la vida de Didier Fassin (2009), como la toma de medidas gubernamentales que impactan de manera subjetiva en la vida y la muerte y, la concepción de género como fenómeno performativo de Judith Butler, (2009) enmarcan el enfoque teórico del análisis planteado.

Esta contribución se propone desde una perspectiva comparada el análisis de dos modelos distintos de políticas de cierre de centros educativos como respuesta a la Covid19 en el marco europeo, el modelo español y el modelo sueco. Las siguientes preguntas de esta investigación son:

¿En qué tipo de contextos de bienestar social surgen los modelos políticos de cierre de centros educativos en España y en Suecia?

¿Qué argumentos legitiman la elección de los modelos políticos de cierre de escuelas en España y en Suecia?

¿Qué modelos políticos de cierre de centros educativos se implementan en España y en Suecia?

¿Qué impactos han tenido los modelos políticos de cierre de escuelas en la igualdad de género en España y en Suecia?

¿Qué similitudes y diferencias se observan entre España y Suecia con respecto a los modelos políticos de cierre de centros educativos y de sus impactos en las desigualdades de género?

Para llevar a cabo el estudio que da respuesta a las preguntas previamente planteadas se ha realizado análisis de: 
- Datos estadísticos en el nivel nacional de la epidemia de Covid-19 durante el período marzo-noviembre 2020.

- Datos estadísticos y de informes a nivel nacional sobre la equidad de género en ambos países.

- Tipo secundario de informes producidos por las autoridades nacionales e internacionales sobre la epidemia de Covid-19 durante el período marzonoviembre 2020.

- Texto sobre documentos nacionales del Ministerio de Educación y de las Juntas nacionales de Educación relacionados con la decisión de cerrar y reabrir escuelas durante el período de marzo de 2020 a noviembre 2020.

Los datos estadísticos e informes se han seleccionado y recogido a partir de diversas fuentes ministeriales o autoridades nacionales e internacionales sobre la evolución de la Covid-19, las desigualdades de género y las medidas de cierre de escuelas. Si bien los datos analizados se han recogido de fuentes de información relativamente fidedignas como los Ministerios y Juntas Nacionales de Educación y Salud, pueden existir diferencias a partir del método utilizado en la recolección de datos estatales, así como por su sistematización y publicación incipiente.

Esta contribución comprende seis secciones. La primera introduce la problemática y el objetivo de la investigación. La segunda sección presenta las bases teóricas que la sustentan. En la tercera y cuarta secciones se abordan respectivamente el caso español y el sueco. La quinta sección aglutina algunos de los impactos de la Covid-19 y su relación con las políticas de cierre de centros educativos desde una perspectiva de género y comparada. En último lugar, se discute el análisis de ambos casos a partir del marco teórico, así como se proponen futuras líneas de investigación a partir de la reflexión final de las dos últimas secciones.

\section{Políticas de cierre de centros educativos como formas de gobernabilidad}

Esta investigación parte de conceptos diferentes pero que articulados son complementarios: la concepción de Didier Fassin de las políticas entendidas como formas de gobernabilidad que regulan y diferencian la vida y la muerte de las personas y la concepción de Judit Butler (2009) de género como fenómeno performativo.

En relación a Didier Fassin (2009), esta investigación analiza las políticas de cierre de centros educativos como una forma de biopolítica que tiene como objetivo regular tanto la vida, como la muerte, transformando y diferenciando a los individuos y grupos de diferentes formas en las distintas sociedades.

Fassin parte del concepto de biopolítica de Foucault entendida como la «... regulación de las poblaciones a través de técnicas de conocimiento e intervención» (2009, p.57). No obstante, Fassin da un paso más y propone entender la biopolítica como una forma de gobernabilidad no solo en términos de regulación, sino como una forma de diferenciación de individuos y grupos ante la vida y la muerte. Problematiza el enfoque de Foucault limitado a las técnicas de gobernabilidad insertadas en la sociedad neoliberal y propone un análisis de las biopolíticas centrado en las desigualdades y la falta de reconocimiento 
tanto en lo que respecta la vida, como la muerte de ciertos individuos y grupos en las diferentes sociedades. De este modo, el cuerpo teórico de Fassin (200) desde un enfoque postfocultiano comprende la biopolítica como un proceso normalizador que interviene en las vidas y produce desigualdades. La medida del cierre de centros educativos es una medida normalizadora que, desde este enfoque, puede producir desigualdades e interviene en las vidas de las personas, ya que, estudios recientes sobre de la Covid-19 (Drephal et al., 2020; Centrum för Epidemiologi och Samhällsmedicin, 2020) demuestran una diferenciación en los impactos en los diferentes grupos sociales. De este modo, argumentamos en esta investigación que el enfoque de biopolítica de Fassin (2009) es particularmente pertinente para el análisis de los impactos del cierre de centros educativos desde una perspectiva de género que preste atención a las consecuencias de estas medidas educativas en la vida de las mujeres en España y Suecia.

La concepción de Butler (2009) del género como un fenómeno performativo es además de interés para esta investigación, ya que, nos permite focalizar la mirada interpretativa sobre la base de la forma en que las medidas educativas en tiempos de Covid-19 diferencian y califican individuos y grupos de acuerdo con su sexo. Para Butler (2009) la performatividad de género implica un proceso en el que algunos cuerpos se producen como sujetos reconocibles mientras que, otros no son representados e inteligibles. En este grupo de organismos que se evalúan como no representados para su reconocimiento, Butler, incluye a las mujeres, las personas queers, personas transgéneros, las personas pobres y las personas apátridas.

La integración tanto de Fassin (2009), como de Butler (2009) en nuestro estudio, proporciona herramientas de análisis teórico que permiten investigar los modelos políticos de cierre de centros educativos como una forma de biopolítica que produce desigualdades de género y que califica y reconoce de forma diferente a hombres y mujeres en tiempos de pandemia.

\section{El caso español}

La estructura del siguiente punto viene determinada por las preguntas de investigación que son las que marcan la integración o el ensamblaje de la teoría con el análisis de la realidad. Partimos del análisis del modelo de bienestar español-para comprender en qué contextos aterrizan o son desarrolladas las políticas de respuesta a la Covid-19continuamos con un análisis sobre el impacto en la salud según género en España, para cerrar con el análisis de las políticas de cierre de escuelas y el impacto biopolítico de estas medidas en la igualdad de género.

\subsection{El modelo de bienestar español}

El régimen del bienestar español es un modelo de vía media que se encuentra a medio camino entre el modelo conservador y el modelo socialdemócrata (Almeda y Sarasa, 1996). Navarro (2006) describe las causas del escaso desarrollo del modelo de bienestar español, frente a sus homólogos europeos socialdemócratas, debido a la tradición heredada del franquismo nacionalcatólico, el rol de las familias como principales instituciones del bienestar y la relación de los poderes de clase y de género. El autor enfatiza en la práctica inexistencia de servicios universales de ayuda a las familias, las deficiencias que sufren los servicios de escuelas infantiles, los escasos servicios domiciliarios para personas dependientes o mayores, personas con diversidad funcional y residencias. 
El modelo de bienestar democrático comenzó a desarrollarse en el período 19821996, bajo los gobiernos del Partido Socialista Obrero Español (PSOE), introduciendo importantes reformas para la racionalización de los servicios de pensiones, las bases de la cobertura nacional sanitaria, la universalización del derecho a la educación en términos de igualdad de oportunidades y la obligatoriedad educativa hasta los 16 años, entre otras medidas (Moreno, 2001).

Durante la década de los 90, el sector servicios creció exponencialmente y supuso posibilidades de empleo para mujeres, jóvenes y personas en desempleo de larga duración. Como consecuencia de la incorporación de la mujer al mundo laboral y su responsabilidad mayoritaria sobre el cuidado de los hijos, se sucedieron problemas de conciliación familiar (Moreno y Mari-Klose, 2016). Las mujeres españolas como «supermujeres» pasan a desempeñar tareas no remuneradas relacionadas con los cuidados del hogar y de las personas dependientes, junto con trabajos asalariados (Moreno, 2002). Peterson (2009) analiza, la relación entre el género y las políticas del Estado de Bienestar español, e incide, en que el modelo sustentador de las familias españolas transita del modelo varón/sustentador a un modelo sustentador/dual, en el que mujer y hombre trabajan fuera de casa. La autora revela cómo la incorporación de la mujer al trabajo en España está representada por la mujer heterosexual de clase media y la sociedad del bienestar depende de otras cuidadoras, como son las abuelas y las mujeres inmigrantes. Especialmente para la conciliación laboral en las edades más tempranas de los hijos, pues la escolarización infantil entre las edades de 3 a 5 años tiene desde hace décadas un carácter universal (Ancheta-Arrabal, 2015).

Durante los gobiernos socialistas de José Luis Rodríguez Zapatero (2004-2011) se trataría de dar respuesta a los grupos vulnerables y ampliar el Estado de Bienestar. Para ello se activó el programa Educa3 ${ }^{1}$, ayudas para la natalidad, la Ley de Dependencia y las ayudas para la emancipación de los jóvenes (del Pino et al., 2014). Tras la crisis económica y financiera del año 2008 estas reformas serían paralizadas o no iniciadas.

Las políticas desarrolladas en los gobiernos del partido conservador español (20112018) han estado marcadas por la crisis económica del año 2008 y las políticas de austeridad europeas que supondrían un deterioro del Estado del Bienestar español (Picatoste, 2018). Se redujo el presupuesto a las Comunidades Autónomas (CCAA), se flexibilizó el despido en favor de las empresas, se aplicaron recortes a la educación y se introdujo el copago sanitario (del Pino et al., 2014). A esta crisis del Estado de Bienestar español se le uniría la crisis de confianza en las instituciones. Datos recogidos en un informe muestran que los españoles entre 2008 y 2016 habían perdido la confianza en los políticos disminuyendo 30 puntos porcentuales respecto de la anterior década (Fundación BBVA, 2016).

El 30 de diciembre del año 2019 formaciones de la izquierda política-UnidasPodemos y PSOE-llegaron a un acuerdo de gobierno de coalición. Ambos grupos parlamentarios desarrollarían un documento en el que se recogía toda una serie de intenciones políticas en torno a la mejora del Estado del Bienestar. Parte de sus propuestas versan sobre: elaboración de un Estatuto de los trabajadores, derogación la reforma laboral del año 2012, fomentar la conciliación laboral, proteger a las familias, etc. (PSOE/UnidasPodemos, 2019).

$1 \quad$ Es el primer programa integral para la creación de nuevas plazas educativas para niños y niñas de o-3 años en España que buscaba mejorar las condiciones para la conciliación laboral de las mujeres. 
Tras el estallido de la crisis del coronavirus las políticas están siendo dirigidas a paliar los efectos de la pandemia. El gobierno ha especificado su posición para la salida de la crisis económica rechazando el modelo de austeridad aplicado tras la crisis del año 2008 (Gobierno de España, 202). Entre las políticas desarrolladas por el gobierno de España para paliar los efectos de la Covid-19 destacan: el Ingreso Mínimo Vital para personas en situación de vulnerabilidad económica, paralización de desahucios, prohibición de despidos, ampliación de las protecciones por desempleo, ayudas a familias en situación de vulnerabilidad, becas comedor, etc. (Gobierno de España, 2020, p.1).

\subsection{El avance de la Covid-19 en el contexto español}

Según la Red Nacional de Vigilancia Epidemiológica (RENAVE) de España, a 25 de noviembre de 2020, la proporción mayor de casos contagiados por coronavirus se da en el grupo de 15 a 59 años (68 \% del total), siendo este grupo el más representado, con un $21 \%$ de los casos, donde destaca que un $52 \%$ de estos son mujeres y que la mediana de edad está situada en 41 años. Con respecto a la distribución por sexo y edad, los casos de Covid-19, están sobrerrepresentados en los hombres de 15-39 años, en mujeres de 15-49 años y en mayores de 89 años para ambos sexos, pero especialmente en mujeres (RENAVE, 2020). En relación con las tasas de mortalidad por Covid-19, algunos estudios señalan que el porcentaje es mayor en hombres que en mujeres (del Río-Lozano y García-Calvente, 2020). Otros estudios destacan que los informes del Ministerio de Sanidad español tienen un cierto valor, pero son incompletos en relación con la susceptibilidad al virus por sexo y género, por lo que su invisibilidad ofrece una óptica inconclusa en cuanto a dicha relación en España (Ruíz-Cantero, 2020).

En general, las cifras que hacen referencia a un mayor caso de contagios por Covid-19 en el conglomerado demográfico de las mujeres están motivadas por la función atribuida a éstas en la sociedad española como cuidadoras, así como que los sectores en los que se concentran las profesiones en primera línea de lucha contra el coronavirus están altamente feminizadas, como es el de la sanidad. De acuerdo con los últimos datos de la Encuesta de Población Activa (EPA), las mujeres representan el 66 \% del personal sanitario que asciende hasta el $84 \%$ en el caso de las enfermeras (Instituto de la Mujer, 2020, p. 5). Los porcentajes de participación de mujeres y hombres son similares en los establecimientos residenciales para mayores y personas dependientes, donde se han dado los casos más graves y el mayor número de fallecimientos (INE, 2020). Otras actividades en los que la representación femenina es ampliamente superior a la masculina son los de: asistencia a personas dependientes, educación, hostelería, peluquería y comercios, lo que las expone a una mayor tasa de contagios (EIGE, 2020a).

\subsection{Políticas nacionales de cierre de escuelas en España.}

El 14 de marzo de 2020 en España se declara el estado de alarma mediante el Real Decreto 463/2020 que supuso la limitación de los desplazamientos exceptuando las actividades de primera necesidad. Las actividades laborales que se pudieran realizar de manera telemática debían transitar hacia esta modalidad. Como ha recogido un informe publicado por el Centro Superior de Investigaciones Científicas (CSIC) en junio de 2020, la decisión de aplicar un confinamiento de estas características vino motivada tanto por las actuaciones llevadas a cabo en China o en Nueva York como por la propia historia del virus y su contagio por vía aérea. La idea central de la aplicación del confinamiento 
descrito era evitar el contacto entre personas y según cifras del CSIC (2020, p. 24) «el confinamiento durante la primera oleada probablemente salvó la vida de 450.000 personas en España».

El objetivo principal recogido en el Real Decreto 463/2020 fue poner en el centro la salud de las personas. El primer período de aplicación y vigencia del estado de alarma español tuvo una duración de 15 días con naturaleza prorrogable tras la evaluación de las necesidades en relación con el número de contagios y de muertes. De este modo, el confinamiento por la «vía dura»-cierre de todas las actividades que no sean imprescindibles o de primera necesidad y prohibición de la circulación de las personas en la vía pública a excepción de la necesidad de realizar actividades estrictamente necesarias-se prolongó hasta el día 21 de junio de 2020, cuando se volvió a un estado denominado de nueva normalidad con una serie de medidas restrictivas. La naturaleza del Estado español organizado y descentralizado en 17 CCAA, las dota de capacidad de gobernabilidad, gestión y administración sobre la crisis sanitaria derivada del coronavirus, entre otras competencias como la educación. En la desescalada, las CCAA pasaron por fases (o-3) indistintas y con diferentes niveles de control social y sanitario desarrolladas conforme al Plan para la transición hacia una nueva normalidad acordado en el Consejo de Ministros español el 28 de abril de 2020 y recogido en el art. 3 del Real Decreto 514/2020, de 8 de mayo.

Ambos Reales Decretos recogen las disposiciones en relación con la situación en la que la educación quedaba tanto durante la «vía dura» del confinamiento como, en la transición hacia la nueva normalidad. Junto a la Orden EFP/365/2020, de 22 de abril, que se establecieron el marco y las directrices de actuación para el tercer trimestre del curso 2019-2020 y el inicio del curso 2020-2021, ante la situación de crisis ocasionada por el Covid-19.

En cuanto a educación, el artículo 9 del Real Decreto 463/2020 declaraba:

Artículo 9. Medidas de contención en el ámbito educativo y de la formación.

1. Se suspende la actividad educativa presencial en todos los centros y etapas, ciclos, grados, cursos y niveles de enseñanza contemplados en el artículo 3 de la Ley Orgánica 2/2006, de 3 de mayo, de Educación, incluida la enseñanza universitaria, así como cualesquiera otras actividades educativas o de formación impartidas en otros centros públicos o privados.

2. Durante el período de suspensión se mantendrán las actividades educativas a través de las modalidades a distancia y «online», siempre que resulte posible.

Dichas medidas, ponen en el centro de la función educativa y de los cuidados de los hijos a las familias y, en menor medida, al profesorado que se ha visto forzado a reinventarse y adaptar las pedagogías y evaluaciones del alumnado en una situación de transición forzada de la docencia presencial hacia la docencia íntegramente online.

La decisión política del cierre de escuelas estuvo fundamentada en la saturación del sistema sanitario español y del número de contagios y muertes que se estaban experimentando, siendo España-seguida de Italia-dentro de los países de la Unión Europea (UE), según datos del Eurostat (2020a), el país con más muertes por habitante derivadas de la infección por coronavirus en la declarada primera ola de la Covid-19.

Según el informe Panorama de la Educación 2020 de la OCDE, los centros escolares españoles permanecieron cerrados durante 16 semanas, frente a la media de 14 semanas de los países de la organización. Al mismo tiempo la OCDE (2020) destaca cómo en 32 de los 46 países analizados los alumnos volvieron a las aulas y los sistemas educativos se pusieron en funcionamiento a partir del mes de mayo. Ahora bien, en España, esta 
medida no fue generalizada, ya que mediante la Orden EFP/365/2020, de 22 de abril, solo se contemplaban las actividades que pudieran ser llevadas a cabo de manera presencial o su naturaleza así lo exigieran como eran: las sesiones de información y orientación para el alumnado de las etapas de $4^{\circ}$ de la Educación Secundaria Obligatoria y del Bachillerato y las pruebas de evaluación para el acceso a la universidad. La flexibilización del retorno a las aulas quedaría sujeta, pues, a la situación sanitaria.

Una vez más, el gobierno de España mediante la Orden EFP/365/2020 priorizaría la preservación de la salud pública de los ciudadanos. La citada Orden venía a sistematizar las medidas que debían desarrollarse durante el tercer trimestre del curso 2019/2020 y el inicio del curso 2020/2021. La apertura de dichos centros sería para que el profesorado y el personal de limpieza y administrativo llevasen a cabo las actividades de adecuación de espacios para respetar el aforo y medidas de distancia social y desinfección.

En el Plan de Desescalada publicado el 28 de abril del año 2020 se introducirían otras cuestiones relativas a la educación. En este caso se fijaban en la fase 2 de desescalada, con mayores índices de control de la pandemia, algunas excepciones para reabrir centros educativos con tres propósitos: actividades de refuerzo, garantizar que los niños menores de seis años puedan acudir a los centros en caso de que ambos padres tuvieran que trabajar presencialmente y celebración de la EBAU (Evaluación del Bachillerato para el Acceso a la Universidad).

En líneas generales, la toma de decisiones política en España sobre el cierre de centros educativos por lo que entendemos por «vía dura» del confinamiento, vino determinada por la situación sanitaria y el desborde de las Unidades de Cuidado Intensivo (UCI) de los hospitales. Pero uno de los debates que se han abierto en la sociedad española de manera intensa entre las formaciones de gobierno en el Parlamento y en los medios de comunicación ha sido si esta toma de decisiones era pertinente y basada en supuestos científicos, así como la existencia o no de un Comité Científico o de Expertos en la Covid19 (Newtral, 2020). Con todo, la confianza de los españoles en la toma de decisiones políticas durante la pandemia reflejada en una encuesta subiría de 4 puntos a 4.8 entre el mes de abril y julio (Eurofound, 2020a, p.54).

Atendiendo a esta medida biopolítica del cierre de centros educativos y su impacto desde una perspectiva de género se torna costoso evaluar sus repercusiones debido a la falta de datos estadísticos (del Río-Lozano y García-Calvente, 2020) y de estudios que relacionen estos cierres con las implicaciones que se pretenden estudiar. No obstante, algunos datos estadísticos que sí han sido recogidos sobre el impacto de la Covid-19 en el género, pueden estar relacionados con el cierre de los centros educativos, como se expone a continuación.

Castellanos-Torres et al. (2020) apuntan a que las consecuencias del cierre de los centros educativos en España han impactado en un aumento de las tareas de cuidados no remunerados y a que las mujeres se vean superadas en las tareas de cuidado y tengan percepciones negativas sobre las atenciones a sus hijos e hijas durante el confinamiento. A este respecto, según un estudio llevado a cabo por la Fundación Family Watch sobre entrevistas a más de 1.774 hogares, han sido las mujeres las que han soportado las mayores cargas de trabajo en el hogar y de ayuda a sus hijos con las tareas y actividades escolares (Fundación Family Watch, 2020a). Otra encuesta realizada a 550 hogares por la misma Fundación ha recogido las percepciones de las familias sobre si la educación a distancia durante el confinamiento ha mejorado la conciliación, en la que el 35,4 \% de las mujeres decían no haber mejorado y el 33,2 \% percibía que continuaba igual (Fundación 
Family Watch, 202ob). A la par, el 86,8 \% de las familias declaraban que la educación online condicionaba su vida, ya que las mujeres no se sienten preparadas para orientar a sus hijos y, aún menos, utilizar medios tecnológicos (Fundación Family Watch, 2020b). Condiciones que se agravan en las familias migrantes que desconocen el idioma y los hogares de bajos recursos económicos, en los que el 54 \% de las personas que ayudan a sus hijos con las tareas académicas son las mujeres, frente al $21 \%$ representado por los padres (Save The Children, 2021).

A la problemática anterior reseñada, cabe sumar las cuestiones relacionadas con el empleo femenino en España desde una perspectiva de género. A principios del año 2020, según datos de Instituto Nacional de Estadística (INEa) recogidos para el trimestre cuatro del año 2020, se registró la tasa con mayor crecimiento de desempleo femenino, la cual estaba situada en un 15,7 \% en el año 2019 y en febrero del año 2020 en un 18,4 \%, agrandándose a su vez la brecha de desigualdad en un 14,2 \%, siendo la mayor tasa de la UE. A las consecuencias directas provocadas por la Covid-19, se suman también factores agravantes del desempleo y que impactan de manera diferente en mujeres y hombres como son: la elevada tasa de temporalidad, la dependencia del turismo, el tejido empresarial formado por pymes y autónomos/as y la brecha en la tasa de empleo de las mujeres (INE, 2020b). Según datos de Eurostat (2020b), el riesgo de perder el trabajo tras la pandemia del coronavirus en los países de la UE queda retratado de manera particular en países como España en el que la probabilidad de perder el trabajo es dos o tres veces mayor para las personas de bajos ingresos. El menor incremento del desempleo femenino en relación con el masculino registrado al inicio de la pandemia no ha garantizado una mejora de la empleabilidad y expectativas de futuro para las mujeres, ya que los sectores del comercio, turismo y hostelería son los más afectados y la recuperación de actividad será más lenta y dilatada en tiempo (Instituto de la Mujer, 2020, p. 10). A su vez, destaca el sector precarizado de las trabajadoras del hogar, en el que la existencia del despido por desistimiento, la no inclusión plena en el régimen general de la Seguridad Social, el no reconocimiento de la prestación por desempleo y el elevado nivel de exposición al contagio, las sitúan como uno de los colectivos más vulnerables. Castellanos-Torres et al. (2020) destacan que el rol social de la mujer española como cuidadora y el cierre de los centros educativos interfiere en la empleabilidad y posibilidades de conciliar el trabajo de la mujer con estos cuidados. En un informe reciente sobre el impacto de la Covid-19 en el género, contempla que las mujeres son las principales cuidadoras de los hijos e hijas y que el cierre de escuelas puede afectar a su condición laboral por necesidades de conciliación, por lo que el Gobierno de España ha establecido el derecho a la flexibilización y reducción de la jornada laboral de las personas que cuenten con hijos e hijas y se vean afectadas por este cierre (Instituto de la Mujer, 2020). En este sentido, las ayudas del gobierno español que proveerían de un fondo de 300 euros transferido a las CCAA para apoyar a las familias en tareas de cuidados no han parecido ser suficientes (Gobierno de España, 2020, p.1). A ello cabe sumar que las ayudas informales para la conciliación, como el apoyo en los abuelos para el cuidado de los hijos que han sido un grupo de riesgo de contagio, no han permitido su continuidad, sumado, al miedo al riesgo de contagio que ha hecho decantarse a los hogares por no contratar vías formales de cuidados, como a personas externas (Fàbregues, 2020).

En relación con la salud mental, física y bienestar familiar, los datos muestran cómo tras la declaración del confinamiento en España vía el Real Decreto 463/2020 de 14 de marzo de 2020 «las llamadas al 016 (teléfono de información y de asesoramiento en 
violencia de género) han aumentado un 10,5 \%y las consultas on-line un 182,93\% con respecto al mes de marzo del año anterior» (Ruíz-Pérez y Pastor-Moreno, 2020, p.1). Lorente-Acosta (2020) destaca como el confinamiento y encierro permanente con los maltratadores intensifica el control y el aislamiento social de las víctimas, una cuestión que se relaciona con el cierre de centros educativos y el aumento de la violencia intrafamiliar durante el período que fue de marzo a junio de 2020. En este caso, el aumento de la violencia de género durante el confinamiento derivó en la aprobación del Real Decreto-ley 12/2020, de 31 de marzo, de medidas urgentes en materia de protección y asistencia a las víctimas de violencia de género, a propuesta del Ministerio de Igualdad y el Ministerio del Interior. En abril de 2020 el gobierno (Eurofound, 2020b) lanza un nuevo programa con el objetivo de dar una solución habitacional inmediata a las personas víctimas de violencia de género, las personas desalojadas de su hogar habitual, las personas sin hogar y otras personas especialmente vulnerables. Empero, los signos de degradación de la salud mental en mujeres no solo están relacionados con la violencia de género, sino también con todas las cargas en los cuidados anteriormente descritas, como el deterioro de sus condiciones laborales.

En resumen, la biopolítica de cierre de centros educativos en España de manera generalizada durante el confinamiento ha supuesto, en relación con los datos recogidos, una medida que ha impactado en la vida de las mujeres en múltiples esferas, si atendemos a que en el modelo español del bienestar la escuela representa un espacio que permite a las familias compatibilizar su vida laboral, de cuidado y salud en relación con sus hijos. Así, se muestran relaciones de cómo se exacerban desigualdades de género previas, entendidas en términos de corresponsabilidad, permanencia y calidad del trabajo femenino y conciliación en una sociedad de bienestar familiarista tradicional y de escaso desarrollo.

\section{El caso sueco}

La estructura del siguiente punto sigue la misma disposición y objetivos del anterior punto para poner en relación los textos, discursos e impactos de la Covid-19 en el contexto sueco desde una perspectiva comparada. Partimos del análisis del modelo de bienestar sueco, continuamos con un análisis sobre el impacto en la salud según género en Suecia, para cerrar con el análisis de las políticas de cierre de escuelas y el impacto biopolítico de cierre de escuelas en la igualdad de género.

\subsection{El modelo de bienestar sueco}

La sociedad sueca está basada en un modelo universal de bienestar social en el cual «... todos los habitantes del país pueden acceder a la misma oferta de servicios (de buena calidad), en función de sus necesidades y preferencias, con independencia de su nivel de ingresos, posición social o residencia ...» (OMS, 2009, p.9, traducción propia).

Este modelo universal de prestaciones sociales calificado por Esping-Anderssen (1990) como el modelo socialdemócrata fue introducido en la Suecia de la posguerra a través de diversas reformas políticas y sociales basadas en un monopolio estatal de naturaleza intervencionista y predominio del sector público en la gestión en las áreas del bienestar social.

El establecimiento de una cobertura social amplia, financiando con recursos públicos los servicios del cuidado de personas dependientes, contribuyó a la gran participación de las mujeres en el mercado laboral. Muestra de ello son los datos de ocupación laboral 
de las mujeres entre 25 y 64 años que en 2019 alcanzó un 81,9 \%. Si bien, el mercado laboral sueco muestra todavía una evidente diferenciación por género, encontrándose las mujeres más representadas en profesiones de cuidado de personas y los hombres en profesiones técnicas y de ingeniería (Folkhälsomyndigheten, 2020a).

A mediados de la década de los 80 del siglo XX, el modelo sueco de bienestar social universal fue objeto de una reforma neoliberal que transformó drásticamente el rol monopólico del Estado como proveedor y garante de los derechos sociales de los ciudadanos. Iniciada por la llamada «revolución de noviembre» y liderada por un gobierno socialdemócrata en 1985 que liberalizó los préstamos bancarios (Hagberg et al., 2006; Sveriges Riksbank, 1999). Seguidamente, se desregularizaron los servicios eléctricos, telecomunicaciones, transporte terrestre, servicio de salud, cuidado de personas dependientes y la educación (Bjurek, 2000). De esta forma, se intensificó considerablemente la mercantilización de los servicios constitutivos de la sociedad del bienestar y se puso fin al monopolio estatal como garante de dichos servicios (Bjurek, 2000; Lundahl et al., 2013). Junto a este proceso de desregulación se introduce un modelo de democracia local centrado en la libertad del individuo, transfiriéndose parte de la responsabilidad y el poder de decisión del Estado a los actores locales. De esta manera, se puso punto final al modelo de democracia social centrada en la formación de la ciudadanía que había caracterizado la sociedad de bienestar sueca desde la posguerra (Englund y Quennestedt, 2008). A su vez, la visión de igualdad hegemónica característica de dicho modelo fue remplazada por una de equidad que intentaba combinar un cierto nivel de igualdad entre los ciudadanos con un alto énfasis en la libertad y la responsabilidad individual y el reconocimiento de las diferencias (Francia, 2018).

Los gobiernos conservadores en el poder durante el periodo 2006-2014 intensificaron aún más este proceso de desregulación al introducir políticas de flexibilización del mercado laboral y de liberalización de la inmigración laboral que intensificó la inseguridad laboral al permitir los contratos laborales precarios sin límite temporal (Landsorganisationen y Sverige, 2010). Estas transformaciones han provocado un deterioro de los convenios colectivos de trabajo, así como la aparición de mano de obra barata sueca y extranjera en los sectores de la construcción y de los servicios (Hesselius, 2011).

Se torna evidente que, a pesar de que la epidemia de la Covid-19 ha puesto de relieve la ya existente y creciente brecha entre diferentes grupos sociales y étnicos, la ciudadanía sueca ha mantenido un nivel alto de confianza en sus autoridades (Chang et al. 2020; Esaisson et al. 2020). Esta alta confianza del ciudadano en sus autoridades es una característica del modelo de sociedad de bienestar sueco. Se trata de un modelo, que según una investigación oficial publicada por el gobierno sueco (SOU, 2018, p.38), ha sabido combinar un alto nivel de confianza de la ciudadanía en el orden político y legal con la independencia del ciudadano durante décadas.

\subsection{El avance del Covid-19 en el contexto sueco.}

El primer caso de contagio de Covid-19 en Suecia es registrado a finales de enero de 2020 (Folkhälsomyndigheten, 2020d). Para noviembre del mismo año, la propagación de la epidemia no había podido ser detenida registrándose un continuo avance de la mortalidad por Covid-19. Durante ambos períodos se registró un mayor número de hombres fallecidos por Covid-19 que de mujeres como se desprende de la Tabla 1: 
Tabla 1.

Evolución de la mortalidad por Covid-19 en el período 1 marzo-27 noviembre 2020

\begin{tabular}{llll}
\hline Períodos & Total & Hombres & Mujeres \\
\hline $\begin{array}{l}\text { 1 de Marzo-30 de } \\
\text { septiembre }\end{array}$ & 5985 & 3241 & 2744 \\
\hline $\begin{array}{l}\text { 1 de octubre-27 de } \\
\text { noviembre }\end{array}$ & 696 & 398 & 298 \\
\hline $\begin{array}{l}\text { Total 1 de marzo-27 de } \\
\text { noviembre }\end{array}$ & 6681 & 3639 & 3042 \\
\hline
\end{tabular}

Fuente: Elaboración propia a partir de Socialstyrelsen (2020) y Folkhälsomyndigheten (2020b)

Si bien, Suecia sigue siendo un país que internacionalmente se distingue por su alto nivel de igualdad social, la brecha económica entre los diferentes grupos sociales se ha ampliado en las últimas décadas como consecuencia de las reformas políticas y económicas introducidas en este periodo. Según un informe de Save the Children (2020), esta brecha económica afecta en especial a los hogares monoparentales y a los ciudadanos de origen extranjero, con riesgo de acentuarse debido a la actual pandemia.

Una investigación basada en el análisis de las estadísticas de fallecimientos por este virus en mayo de 2020 (Drephal et al., 2020) demuestra que factores como ser hombre, disponer de menos ingresos, de menos educación y no estar casado predicen de forma independiente no solo un mayor riesgo de muerte por Covid -19, sino de todas las demás causas de muerte.

Un informe del Centro de Epidemiologia de la región de Estocolmo (Centrum för Epidemiologi och Samhällsmedicin, 2020) evidencia el impacto desigual de la epidemia en los diversos grupos sociales, hallando entre los más afectados a hombres, ancianos, grupos con un nivel socioeconómico más bajo, personas de origen extranjero o residentes en zonas geográficas determinadas. Este informe confirma la relación entre clase social y riesgo de morir por Covid-19 al verificar un riesgo cuatro veces mayor de mortalidad para el grupo social con menos ingresos comparado al grupo social con más ingresos en Suecia. El mismo Informe asocia como factor de riesgo, el trabajo en sectores del mercado laboral donde no es posible implantar el teletrabajo, como sucede para el personal dedicado a la salud y al cuidado de ancianos.

Las diferencias de género son, a su vez, evidentes con respecto a las personas ingresadas en terapia intensiva y los casos de contagios. En el caso de terapia intensiva, los hombres ingresan más en este tipo de tratamiento (2.316) frente a las mujeres (892). En el caso del total de casos diagnosticados por género, los hombres estarían por debajo con 112.744 y las mujeres con 130.328 (Folkhäsomyndigheten, 2020b).

Asimismo, un estudio sobre la incidencia de la Covid-19 elaborado a partir de estadísticas de marzo-mayo del 2020, evidencia diferencias según el lugar de nacimiento de los habitantes en Suecia (Folkhälsomyndigheten, 2020c). La incidencia está calculada de acuerdo con la cantidad de casos cada 100.00o habitantes, representada en la Tabla 2, mostrando una mayor incidencia en personas nacidas fuera de Suecia que, en las nacidas en el país nórdico estudiado. 
Tabla 2.

Incidencia de Covid-19 en relación con el lugar de nacimiento.

\begin{tabular}{lllll}
\hline $\begin{array}{l}\text { Lugar de } \\
\text { nacimiento }\end{array}$ & $\begin{array}{l}\text { Cantidad en } \\
\text { la población }\end{array}$ & $\begin{array}{l}\text { Incidencia } \\
\text { mujeres }\end{array}$ & $\begin{array}{l}\text { Cantidad en } \\
\text { la población }\end{array}$ & $\begin{array}{l}\text { Incidencias } \\
\text { hombres }\end{array}$ \\
\hline Turquía & 155 & 669 & 234 & 820 \\
\hline Etiopia & 85 & 792 & 76 & 693 \\
\hline Somalia & 257 & 725 & 206 & 593 \\
\hline Chile & 79 & 569 & 96 & 678 \\
\hline Eritrea & 105 & 509 & 113 & 450 \\
\hline Irak & 426 & 632 & 450 & 573 \\
\hline Líbano & 52 & 407 & 100 & 636 \\
\hline Finlandia & 481 & 548 & 263 & 463 \\
\hline Irán & 215 & 568 & 203 & 480 \\
\hline Tailandia & 89 & 261 & 17 & 180 \\
\hline Suecia & 9,343 & 226 & 6,333 & 152 \\
\hline
\end{tabular}

Fuente: Elaboración propia en base a los datos de Folkhälsomyndigheten (2020c)

\subsection{Políticas nacionales de cierre de escuelas en Suecia.}

Suecia se distingue de forma significativa de las estrategias tomadas en otras regiones del mundo, entre ellos del resto de países nórdicos, por oponerse a seguir las recomendaciones de la Organización Mundial de la Salud (OMS), obteniendo una especial resonancia internacional con su estrategia anti-Covid-19.

El modelo sui generis de política anti-Covid-19 se ha caracterizado por su énfasis en la responsabilidad del ciudadano a través de recomendaciones. El objetivo de la política sueca era «...disminuir el ritmo de transmisión, es decir, aplanar la curva del número de personas que enferman» con el objetivo de «atenuar las consecuencias para la ciudadanía y las empresas» así como de «tranquilizar a la población», por lo que el gobierno se limitó a hacer recomendaciones a la ciudadanía sin decretar confinamiento alguno Regeringengskansliet , 2020). Estrategia definida por el propio gobierno como una decisión política de equilibrar costos y efectos de las medidas anti-Covid-19 en la sociedad sueca (Regeringengskansliet, 2020).

A pesar de la posibilidad legal de implementar medidas restrictivas extraordinarias desde el comienzo de la pandemia, Suecia, eligió en cambio una política menos laxa basada en recomendaciones como lavarse las manos, trabajar desde casa y distanciamiento social. A diferencia de la mayoría de los países, desde el inicio, Suecia, evitó imponer la cuarentena, cerrar las escuelas preescolares y obligatorias y recomendar a la población el uso de mascarillas. La estrategia sui generis del gobierno sueco se justifica en términos de «conocimiento de experto» en una sociedad con un alto nivel de confianza en sus representantes y agencias gubernamentales.

A su vez, el gobierno sueco se ha mantenido firme en su línea de prevención y lucha contra la Covid-19, a pesar de las numerosas críticas recibidas por actores nacionales e internacionales. Entre las causas de esas críticas, se pueden citar el alto número de fallecidos en las residencias de ancianos, la baja capacidad de hacer pruebas diagnósticas, y su incapacidad de disminuir la propagación de la epidemia (Dagens Nyheter, 2020; Läkartidningen, 2020; OECD, 2020; Chang et al., 2020) 
En el ámbito educativo, Suecia, optó por un cierre parcial de los centros educativos manteniendo abiertos los preescolares y de educación obligatoria. Por el contrario, el gobierno sueco, recomendó la suspensión de la enseñanza presencial en las escuelas secundarias, instituciones de educación superior, politécnicos y centros de educación de adultos durante el período marzo-agosto 2020. Sin embargo, la llegada de la segunda ola de la epidemia de la Covid-19 en octubre-noviembre, llevó a muchas de las instituciones de educación secundaria y universitaria a volver a impartir clases en modalidad a distancia reduciendo de nuevo, o eliminando totalmente, la enseñanza presencial.

El gobierno sueco justificó su decisión de cierre parcial del sistema educativo argumentando que esta decisión está respaldada por el conocimiento de expertos científicos (Folkhälsomyndigheten, 2020e). En la página web de la Agencia de Salud Pública de Suecia (Folkhälsomyndigheten, 2020e) se muestra esta justificación mediante los siguientes argumentos:

- La falta de evidencia científica que respalde el cierre de centros prescolares y de educación obligatoria como una estrategia para detener la transmisión de Covid-19 en la sociedad.

- La menor existencia de casos de Covid-19 entre niños, jóvenes y personal escolar, junto al rol de la escuela para los niños, las familias y la sociedad.

- El poco impacto que el cierre de estos centros tendría en la propagación de la epidemia.

- Los efectos negativos del cierre de estos centros en los grupos vulnerables, entre ellos los abuelos.

- Los efectos negativos de cierre de estos centros para los trabajadores en los sectores considerados esenciales para la sociedad como los empleados sanitarios.

- La falta de lugares alternativos para el cuidado de los niños

- El rol de los centros educativos como punto de seguridad y estabilidad para el desarrollo de la niñez

- Efectos negativos sin especificar para la sociedad sueca en su conjunto.

Al mismo tiempo, la Agencia de Salud Pública de Suecia (Folkhälsomyndigheten, 2020e) justifica su recomendación de solo cerrar las escuelas secundarias, instituciones de educación superior, politécnicos y centros de educación de adultos como estrategia para detener la epidemia para reducir la congestión en el transporte público que puede considerarse como un riesgo de una mayor diseminación de la Covid-19.

De acuerdo con la Agencia Sueca de Igualdad de Género (Jämställdhetsmyndigheten, 2020) todavía es muy pronto para saber el impacto total de esta pandemia en la igualdad de género debido a la falta de datos estadísticos en todas las áreas de la sociedad de bienestar sueca.

En lo que respecta el mercado laboral la Agencia Sueca de Igualdad de Género (Jämställdhetsmyndigheten, 2020) pronostica un mayor índice de desempleo en los hombres que, en las mujeres tras la epidemia de la Covid-19. Esta mayor representación de los hombres en las estadísticas de desempleo estaba ya presente antes de la pandemia. La mayor demanda de las mujeres en el mercado laboral sueco es debida a la alta segregación de género en el ámbito de trabajo y al hecho de que las mujeres son mayoría 
en los sectores del bienestar público (educación, salud, cuidado de ancianos y discapacitado) tanto ahora, como en el futuro. Es por ello, por lo que estos sectores públicos como educación, salud y cuidado de ancianos y discapacitados siguen dominados por mujeres.

Sin embargo, la inserción en el mercado laboral corre el riesgo de seguir siendo más difícil para los grupos con conexión débil al ámbito del trabajo, entre los que se encuentran las mujeres de origen extranjero y las mujeres con discapacidades o con capacidades laborales reducidas (Jämställdhetsmyndigheten, 2020).

Es lo que respecta al caso sueco, los efectos de la Covid-19 en relación con las medidas educativas y la desigualdad de género pueden ser diferenciados en la siguiente forma:

a) Impactos del cierre de centros educativos de nivel medio y superior

De acuerdo con la Agencia Sueca de Igualdad de Género (Jämställdhetsmyndigheten, 2020), todavía es muy pronto para saber el impacto total de esta pandemia en la igualdad de género debido a la falta de datos estadísticos en todas las áreas de la sociedad de bienestar sueca. Sin embargo, se registra una incidencia mayor de las enfermedades mentales entre las mujeres que en los hombres, tanto en edad laboral como mayores. También, el índice de mala salud mental es mayor en las mujeres jóvenes que en los jóvenes varones de la misma edad, siendo uno de los motivos del cierre de escuelas secundarias superiores, centros de estudio superior y universidades (Jämställdhetsmyndigheten, 2020). El aumento de la violencia de género y familiar incide a su vez en mayor medida en las mujeres que en los hombres. El cierre de los centros educativos de nivel de educación secundaria corre el riesgo de aumentar el control de niñas y jóvenes, así como la falta de libertad de las jóvenes que viven en situaciones de violencia y opresión relacionadas con la intensión de salvaguardar el «honor» de las familias. Para este grupo la escuela les brinda un lugar de seguridad y mayor libertad al que no se puede ahora acceder al ordenar el gobierno su cierre (Jämställdhetsmyndigheten, 2020).

El cierre de los centros educativos en el nivel medio ha llevado consigo un aumento del trabajo docente al tener que adaptar la enseñanza y evaluación presencial a la digital (Fahlén, 2020). Por el contrario, la posibilidad de trabajar a distancia ha supuesto a su vez en un menor contagio en el grupo de profesores de la escuela secundaria (Vlachos et al., 2021). Es de interés notar que en este colectivo docente se caracteriza por una representación relativamente equitativa de mujeres (52 \%) y de hombres (48 \%) (SCB, 2020). Es por ello por lo que podemos concluir que el cierre de centros escolares del nivel secundario no ha contribuido directamente a una mayor desigualdad de género en este sentido.

b) Impactos del NO cierre de los centros educativos del nivel obligatorio

La apertura de los centros de educación prescolar y obligatoria ha contribuido a la igualdad de género en un mercado laboral que registra un alta de participación femenina.

Sin embargo, la apertura de los centros educativos de nivel obligatorio ha tenido impactos negativos para los docentes de la escuela obligatoria. Este colectivo, del cual $75 \%$ son mujeres (SCB 2020), ha sido una de las profesiones más afectadas por el contagio de la Covid-19 (Vlachos et al., 2021).

El grupo de profesores de la escuela obligatoria cuyos centros no fueron cerrados registró el doble de posibilidades de contagio que el de los profesores de secundaria superior que enseñaban a distancia. El colectivo de profesores de escuela obligatoria de los últimos cursos $\left(7^{\circ}, 8^{\circ}\right.$ y $\left.9^{\circ}\right)$ se ubica a su vez entre las profesiones de más riesgo de contagio a nivel nacional. Es de observar, no obstante, que el alto nivel de contagio se registra entre los profesores de los últimos cursos y no de los primeros grados de la escuela obligatoria. Por ello, se concluye que el aumento del riesgo de los docentes está 
en relación con el aumento de la edad de los estudiantes. Otra interpretación del alto contagio entre este grupo docente podría estar en los diferentes modos de interacción entre el personal docente (Vlachos et al., 2021).

Así se puede concluir que la decisión de mantener abiertos los centros educativos de educación obligatoria ha afectado especialmente a un colectivo de profesores con alto nivel de representación femenina como es el profesorado de la escuela obligatoria.

Los efectos negativos de esta diferenciación del profesorado con respecto a las posibilidades trabajar a distancia se agudizaron al elegir Suecia una estrategia nacional de prevención de la Covid-19 basada principalmente en la responsabilidad individual y las recomendaciones.

\section{El impacto en la igualdad de género en perspectiva comparada}

Si bien la presentación de informes por país de los datos desagregados por sexo de Covid19 es variada e irregular en los casos estudiados, se ha podido comparar la incidencia del virus según el género tal y como puede comprobarse en la Tabla 3. En ambos países, a pesar de que en el número total de personas infectadas de Covid-19 la proporción de hombres es significativamente menor, la proporción de hombres fallecidos a causa del virus es mayor indicando una mayor incidencia del virus en esta población en ambos países. Como anteriormente se ha expuesto, son las mujeres las que están al frente de las profesiones de cuidados y las que cuidan en los hogares de los hijos y los familiares dependientes, lo que responde a mayores tasas de contagio femeninas. No obstante, es llamativo que, en los datos de incidencia acumulada tanto para las personas infectadas, como las fallecidas, no se muestren diferencias significativas que cabría esperar cuando las medidas políticas y de contención del virus han sido tan dispares en estos países.

Tabla 3.

Datos del impacto del Covid-19 desagregados por sexo (2020)

\begin{tabular}{|c|c|c|c|c|}
\hline & España & & Suecia & \\
\hline $\begin{array}{l}\text { Datos acumulados de personas } \\
\text { infectadas por Covid-19 (proporción cada } \\
100.000 \text { habitantes) desde } 31 / 12 / 2019 \\
\text { hasta } 28 / 11 / 2020\end{array}$ & 3509.2 & & 2490.2 & \\
\hline \multirow{2}{*}{$\begin{array}{l}\text { Datos acumulados de personas fallecidas } \\
\text { por Covid-19 (proporción cada 100.000 } \\
\text { habitantes) desde 31/12/2019 hasta } \\
\text { 12/03/2021 }\end{array}$} & 154.01 & & 128.53 & \\
\hline & Hombres & Mujeres & Hombres & $\mathrm{Mu}-$ \\
\hline Porcentaje del total de casos confirmados ( \%) & 46.95 & 53.05 & 46.38 & 53.62 \\
\hline Porcentaje del total de defunciones ( \%) & 56.54 & 43.44 & 54.86 & 45.14 \\
\hline
\end{tabular}

Fuente: Elaboración propia a partir de WHO Coronavirus Disease (Covid-19) Dashboard, GlobalHealth5050 (2020), Folkhålsomyndigheten (2020) y Johns Hopkins Coronavirus Research Center (2021). 
En la tabla 4 se comprueba que la brecha laboral es mayor en España que en Suecia, que se mantiene por debajo de la media de la UE. Si bien solo para el trabajo a tiempo completo, pues en el caso del empleo a tiempo parcial, aunque ambos países se sitúan por debajo de la media europea, es Suecia donde la brecha laboral es mayor. En todo caso, la tasa de empleo femenino en España, que ya estaba por debajo de la media de la UE antes de esta crisis, ha disminuido significativamente más que en Suecia.

En esta línea, la variación del número de horas reales trabajadas por las mujeres en el primer trimestre de 2020 con respecto al trimestre anterior y al mismo trimestre del año anterior en Suecia, consigue que no aumente a lo largo del periodo que viene durando la crisis de la pandemia, mientras que, en España, esta diferencia se ha duplicado siguiendo la tendencia de la media de la UE (Tabla 4). Así los datos de una encuesta realizada a 7.00o mujeres españolas, publicada el 18 de febrero de 2021, han mostrado como 1 de cada 4 madres renunció a su trabajo o redujo su jornada laboral para cuidar de sus hijos durante el confinamiento, así como el $74 \%$ de ellas gastó, sus días por derecho a vacaciones, para estar al cargo del cuidado de sus hijos durante la pandemia y el $21 \%$ solicitó una excedencia de trabajo (YoNoRenuncio, 2021). Datos de la misma encuesta han recogido como el $37 \%$ de estas mujeres no pudo desarrollar su tarea laboral mediante la modalidad de teletrabajo, aunque las características de su trabajo lo permitían (YoNoRenuncio, 2021). Como conclusión global, la encuesta muestra como el 73 \% de las mujeres expresaban que la corresponsabilidad en el hogar no había mejorado en España, a diferencia del caso de Suecia donde-según un informe del sindicato de empleados estatales con fecha de mayo del 2020- muestra una actitud más positiva hacia teletrabajo de las mujeres frente a hombres en lo que concierne a sus efectos positivos para llegar a un equilibrio entre el trabajo y el tiempo libre (Fakförbundet ST, 2020).

Incluso sin un estado de crisis como el actual, las responsabilidades del cuidado generalmente recaen en gran medida sobre las mujeres, dado que, antes del brote de Covid-19, las mujeres de la UE dedicaban 13 horas más que los hombres a la semana al cuidado y las tareas domésticas no remuneradas. Con el cierre de escuelas y lugares de trabajo, y la posibilidad de que los parientes mayores se enfermen, es probable que su carga de trabajo no remunerado aumente aún más (EIGE, 2020b, p. 26). 
Tabla 4.

Brechas de género en España, Suecia y media UE en 2020. ${ }^{2}$

\begin{tabular}{|c|c|c|c|c|c|c|}
\hline & \multicolumn{2}{|c|}{ España } & \multicolumn{2}{|c|}{ Suecia } & \multicolumn{2}{|c|}{ Media-UE27 } \\
\hline $\begin{array}{l}\text { Brecha de género } \\
\text { laboral }(2019)^{2}\end{array}$ & \multicolumn{2}{|c|}{11.9} & \multicolumn{2}{|c|}{$4 \cdot 7$} & \multicolumn{2}{|c|}{11.7} \\
\hline $\begin{array}{l}\text { Brecha de género } \\
\text { empleo tiempo } \\
\text { parcial (2019) }\end{array}$ & \multicolumn{2}{|c|}{16.9} & \multicolumn{2}{|c|}{18.7} & \multicolumn{2}{|c|}{21.6} \\
\hline \multirow{2}{*}{$\begin{array}{l}\text { Tasas de empleo } \\
\text { femenino, entre } \\
20 \text { y } 64 \text { años ( \%) }\end{array}$} & 2019 & 2020 & 2019 & 2020 & 2019 & 2020 \\
\hline & 62.3 & 58.0 & 80.2 & 78.1 & 67.5 & 65.9 \\
\hline \multirow{2}{*}{$\begin{array}{l}\text { Variación \% en } \\
\text { el total de horas } \\
\text { trabajadas por } \\
\text { las mujeres con } \\
\text { respecto } 2019\end{array}$} & 2019-T1 & $2019-\mathrm{T}_{4}$ & 2019-T1 & $2019-\mathrm{T}_{4}$ & $\begin{array}{c}\text { 2019- } \\
\text { T1 }\end{array}$ & 2019-T4 \\
\hline & -2.2 & -4.6 & -3.8 & -3.8 & -4.1 & $\begin{array}{c}-5 \cdot 2 \\
-\end{array}$ \\
\hline \multirow{2}{*}{$\begin{array}{l}\text { Brecha de género } \\
\text { riesgo de pobreza } \\
\text { por edad }\end{array}$} & $<65$ años & > 65 años & $<65$ años & > 65 años & $\begin{array}{r}<65 \\
\text { años }\end{array}$ & $>65$ años \\
\hline & -2.19 & 0.16 & 0.95 & -11.79 & -0.62 & -6.13 \\
\hline
\end{tabular}

Fuente: Elaboración propia a partir de Eurostat (2020b).

Así, el cambio de las tareas de cuidado vinculado a la Covid-19 de vuelta a hogares privados tiene efectos negativos más graves en los ingresos de las mujeres, ya que asumen este deber a costa de su participación en el mercado laboral, perdiendo ingresos actuales y futuros. El impacto en este sentido es visible también en relación con la brecha de género en la tasa de riesgo de pobreza por edad según la encuesta EU-SILC ( \%) como se observa en la Tabla 4.

En todo caso, estas diferencias en las políticas y situaciones laborales de las mujeres no se reflejan en los datos del aumento de denuncias de violencia contra la mujer en ambos países donde tanto España, como se indicó en el estudio de caso para este país, como Suecia, han registrado alrededor de un $10 \%$ de aumento durante el año 2020 en la cantidad de llamadas para denunciar casos de violencia contra la mujer (Jämlikhetsmyndigheten, 2021). Igualmente, en lo que concierne la violencia de género contra la infancia se ha registrado un aumento de un $4 \%$ tanto de las denuncias de maltrato contra las niñas de o a 6 años como en las denuncias contra las niñas de 15-17 años (Jämlikhetsmyndigheten, 2021). En líneas generales, y como se ha destacado en el estudio de caso español, el hecho de que se hayan cerrado los centros educativos y las familias hayan confinadas en el ámbito de lo doméstico, ha mostrado una mayor incidencia de violencia sobre las mujeres y las mujeres durante el confinamiento, y un aumento del 20 \% de los índices de ansiedad en las mujeres (Save The Children, 2021).

\section{Reflexiones finales}

El cierre de centros educativos como una forma de gobernabilidad de los ciudadanos ha adquirido, en España y Suecia, formas y alcances diferentes dependiendo de los

$2 \quad$ La brecha de género laboral mide la diferencia entre las tasas de empleo de hombres y mujeres de 20 a 64 años. 
contextos de bienestar social dominante en cada país. En base a la concepción de biopolítica de Didier Fassin (2009) el estudio de los modelos de cierre de centros educativos pone en evidencia la necesidad de relacionar y comprender las medidas de cierre con el contexto de bienestar social en el que surgen. A su vez este análisis comparativo permite ilustrar como en cada sociedad y de forma diferente el cierre o el no cierre de centros educativos pueden resultar en una diferenciación de individuos y grupos en tiempos de pandemia, aunque los estudios desde esta perspectiva interseccional son insuficientes por el momento.

Cómo se desprende de los análisis de los casos, ambos modelos de bienestar social han sufrido alteraciones y remodelaciones en las últimas décadas y ello puede contribuir a un deterioro de las condiciones e igualdad de género en tiempos de pandemia, aunque con diferentes consecuencias debido a que el modelo de bienestar español presenta un escaso desarrollo, frente al modelo de carácter más universalista sueco en el que se cristalizan las políticas de cierre de centros educativos. La crisis de la Covid-19 se inserta en dos modelos de gobernanza política diferenciados y específicos en el momento en el que España con una administración ampliamente descentralizada toma decisiones que para el control de la pandemia centralizadas. En el caso de Suecia partiríamos de un modelo de gobernabilidad basado en recomendaciones e implementado en un sistema educativo de gobernanza descentralizada.

El control de la pandemia desde la visión biopolítica de Fassin ha mostrado como en situaciones de alto contagio poblacional en ambos escenarios, se ha traducido en efectos parecidos en relación con el impacto según género con relación al modo de contagios, es decir, son los hombres los que presentan mayores índices de mortalidad, pero son las mujeres las que se contagian más al trabajar los sectores laborales de cuidados y altamente feminizados. De este modo, las políticas de cierre o no de centros educativos en España y Suecia en formas y con justificaciones distintas, son ejemplos de biopolíticas que pueden influir en la gobernabilidad de la vida y la muerte de los ciudadanos.

El control biopolítico en ambos contextos, si bien, fundamentados en decisiones de control de la pandemia diferentes, produce efectos performativos de género similares en relación violencia sufrida por las mujeres reducidas al ámbito de lo privado, por el mayor control ejercido por los maltratadores en los hogares, ya se trate de un confinamiento por la vía dura en el caso español o un confinamiento flexible en el caso sueco.

Sin embargo, no podemos declarar que las implicaciones de las políticas de cierre de centros educativos hayan tenido los mismos efectos en la desigualdad de género en ambos contextos. En el contexto español, el cierre de todos los centros educativos ha mostrado una agravamiento de la conciliación, una mayor carga en las tareas y cuidados de las mujeres, un deterioro de sus condiciones de salud y un empeoramiento en sus condiciones laborales por no poder combinar las tareas de cuidado con el teletrabajo y la imposibilidad de flexibilizar su jornada laboral en términos generales también determinada por la imposibilidad de terciarizar el cuidado de los hijos en familiares o abuelos; todo ello ha impactado en la vida laboral, emocional y física de las mujeres.

En el caso sueco, la política de no cierre de los centros escolares ha venido justificada en que los centros prescolares y de educación obligatoria son entendidos como instituciones esenciales para la continuidad de las actividades consideradas como vitales a falta de otras alternativas para el cuidado de los niños. En una sociedad en la cual más del $80 \%$ de las mujeres entre 25 y 64 años participan en forma activa en el mercado laboral, solo se ha posible el cierre de estos centros en casos de excepción y solo por 
medidas sanitarias. En este sentido la apertura de estos centros puede ser interpretada como una medida de igualdad de género al facilitar la participación de la mujer en el mercado laboral. Su apertura durante la epidemia puede ser también entendida como una estrategia para combatir el riesgo de un aumento de la violencia familiar dirigida en particular contra las mujeres y los niños. Sin embargo, la decisión política de no cerrar los centros educativos obligatorios también puede ser entendida como mayor riesgo de contagio para el colectivo de profesores de la escuela obligatoria representado en un $75 \%$ por mujeres.

De forma paradójica podemos concluir que la medida de NO cierre de establecimientos en el caso sueco ha contribuido tanto a la igualdad como a la desigualdad de género dependiendo del grupo que se analice. El caso sueco pone en evidencia que las medidas educativas de cierre o no cierre de escuelas dependiendo del nivel escolar, han funcionado como formas de gobernabilidad y diferenciación de los ciudadanos, al exponer un mayor contagio de ciertos profesores y no de otros.

Son notorias las implicaciones en términos biopolíticos e impactos en la igualdad de género en ambos casos, aunque las decisiones políticas hayan sido diferentes. Si bien ambos modelos han puesto en marcha medidas de igualdad de género para mitigar los posibles efectos negativos de las medidas de gobernabilidad de la población durante la pandemia, ambos modelos han contribuido a la producción de desigualdades de género ya existentes en cada sociedad como se ha comprobado en los estudios de caso.

Ahora bien, es necesario especificar que los estudios intersectoriales de género e impactos de la Covid-19 son incipientes. Para finalizar, este estudio comparativo permite poner en evidencia la necesidad de desarrollar investigaciones futuras que profundicen el carácter performativo del género (Butler, 2009) desde una perspectiva interseccional. Como se ha podido comprobar estos estudios son escasos, pero el enfoque de Butler (2009) como cuerpos reconocibles y no reconocibles nos ha permitido poner de relieve el silencio en los estudios sobre los mismos. Para ello se debe tener en cuenta los impactos negativos en términos de mortalidad y contagio de la epidemia en hombres y mujeres migrantes y de minorías étnicas, religiosas y culturales, así como las desigualdades relacionadas con la interacción de género, etnia y clase social. Además, resulta fundamental estudiar tanto las experiencias en el nivel micro como los factores en el nivel macro, entre las que se encuentran las políticas y prácticas en la educación como en otros ámbitos y estructuras de la sociedad (Grant y Zwier, 2017).

\section{7. $\quad$ Referencias}

Almeda, E. \& Sarasa., S. (1996). Spain: Growth to Diversity. En V. George \& G. Taylor. (Eds.). European Welfare Policy: Squaring the Welfare Circle (pp. 155-76). Macmillan.

Ancheta-Arrabal, A. (2015). Comparing Early Childhood Education and Care from a Rights-based Approach. Revista Española de Educación Comparada, 25(2015), 47-63. DOI: 10.5944/reec.25.2015.14783

Bjurek, H., (2000). Avreglering till varje pris? Ledare Ekonomisk Debatt, 28(4), 303304. https://www.nationalekonomi.se/taxonomy/term/2294

Butler J. (2009) Performativity, Precarity and Sexual Politicts. AIBR. Revista de Antropología Iberoamericana, 4(3), i-xiii. 
Centrum för Epidemiologi och Samhällsmedicin (2020) https://www.ces.sll. se/globalassets/verksamheter/forskning-och-utveckling/centrum-forepidemiologi-och-samhallsmedicin/folkhalsoguiden/rapporter-och-faktablad/ rapport-2020.10-socioekonomiska-faktorer-och-covid-19-i-stockholms-lannovember-2020.pdf

Chang, R. , Hong, J. \& Varley. K. (24 de noviembre de 2020). The Covid Resilience Ranking. The Best and Worst Places to Be in the Corona Era. Blomberg. https:// www.bloomberg.com/graphics/covid-resilience-ranking/

Centro Superior de Investigaciones Científicas (CSIC) (2020). Una vision global de la pandemia Covid-19. Qué sabemos y qué estamos investigando desde el CSIC. Gobierno de España.

Dagens Nyheter (2020) Folkhälsomyndigheten har misslyckats - nu måste politikerna gripa in". https://www.dn.se/debatt/folkhalsomyndigheten-har-misslyckats-numaste-politikerna-gripa-in

del Pino, E., Moreno, F.J., y Mari-Klose, P. (2014). La evolución del Estado de bienestar español: un sueño que no se hizo realidad. elDiario.es. https://www. eldiario.es/agendapublica/impacto_social/evolucion-bienestar-espanol-suenorealidad_1_4952273.html

del Río-Lozano, M. y García-Calvente, M.M. (en prensa). Cuidados y abordaje de la pandemia de COVID-19 con enfoque de género. Gaceta Sanitaria. https://doi. org/10.1016/j.gaceta.2020.05.006

Drephal, S.; Wallace, M.; Mussino, E.; Aradhya, S.; Kolk, M.; Brandén, M.; Malmberg, B.; \&, Andersson, G. A (2020). Population-based cohort study of socio-demographic risk factors for COVID-19 deaths in Sweden. Nat. Commun, 2020, 11, 5097.

Englund, T. \& Quennersterdt, A., (2008). Likvärdighetsbegreppet i svensk utbildningspolitik. IN Englund, T. \& Quennersterdt, A. (Eds.), Vadå likvärdighet? Studier i utbildningspolitisk språkanvändning (pp.7-35). Daidalos.

Esaisson, P.; Sohlberg.; J. Gersetti, M.; \& Johansson, B. (2020) How the coronavirus crisis affects citizen trust in institutions and in unknown others: Evidence from 'the Swedish experiment. European Journal of Political Research, 1. doi: 10.1111/14756765.12419

Esping-Andersen, G. (1990). The Three Worlds of Welfare Capitalism. Princeton University, Press.

Eurofound (2020a). Living, working and COVID-19, COVID-19 series. Publications Office of the European Union.

Eurofound (2020b). Work, teleworking and COVID-19'. https://www.eurofound. europa.eu/data/covid-19/working-teleworking

European Institute for Gender Equality (EIGE) (2020a). Gender Equality Index 2020: Digitalisation and the future of work. Publications Office of the European Union. https://eige.europa.eu/sites/default/files/documents/mhaf2ooo1enn_oo2.pdf 
European Institute for Gender Equality (EIGE) (2020b). Covid-19 and gender equality. Economic hardship and gender. Frontline workers. https://eige.europa.eu/covid19-and-gender-equality/frontline-workers

Eurostat (2020a). Weekly death statistics. https://ec.europa.eu/eurostat/statisticsexplained/index.php?title=Weekly_death_statistics\#Dramatic_rise_in_deaths_ in_early_spring

Eurostat (2020b). COVID-19 labour effects across the income distribution. https:// ec.europa.eu/eurostat/web/products-eurostat-news/-/DDN-20201027-2?inherit Redirect $=$ true\&redirect $=\% 2$ Feurostat $\% 2$ Fweb\%2Fcovid-19\%2Flatest-releases

Eurydice (2020) How is Covid-19 affecting schools in Europe? https://eacea.ec.europa. eu/national-policies/eurydice/content/how-covid-19-affecting-schools-europe_en

Fàbregues, S. (6 de octubre de 2020). Género, producción académica y COVID-19. Blog de los Estudios de Psicología y Ciencias de la Educación. https://epce.blogs.uoc. edu/es/genero-produccion-academica-covid/

Fahlén Å. (2020) Det är en ohållbar arbetsbelastning Ledare $i$ Skolvärlden. LärarnasRiksförbund.https://www.lr.se/opinion--debatt/ordforande-harordet/2020/2020-08-28-det-ar-en-ohallbar-arbetsbelastning

Fakförbundet ST (2020). Jobba hemifrån - Är distansarbete här för att stanna? Oktober 2020.

Fassin, D. (2009). Another Politics of Life is Possible. Theory, Culture and Society, 26 (5), 44-6o. https://doi.org/10.1177/0263276409106349

Folkhälsomyndigheten (2020a). Sysselsättning $i$ befolkningen. https://www. folkhalsomyndigheten.se/folkhalsorapportering-statistik/tolkad-rapportering/ folkhalsans-utveckling/resultat/livsvillkor/sysselsattning-i-befolkningen/

Folkhälsomyndigheten (2020b) Bekräfade fall i Sverige-Daglig uppdatering. https:// www.folkhalsomyndigheten.se/smittskydd-beredskap/utbrott/aktuella-utbrott/ covid-19/statistik-och-analyser/bekraftade-fall-i-sverige/

Folkhälsomyndigheten (2020c) Covid-19 Demografisk beskrivning av bekräftade covid-19 fall i Sverige 13 mars-7 maj 2020. https://www.folkhalsomyndigheten. se/contentassets/d6538f6c359e448ba39993a41e1116e7/covid-19-demografiskbeskrivning-bekraftade-covid-19-fall.pdf

Folkhälsomyndigheten (2020d), Bekräftat fall i Jönköping av nya coronaviruset (2019-nCoV).https://www.folkhalsomyndigheten.se/nyheter-och-press/ nyhetsarkiv/2020/januari/bekraftat-fall-av-nytt-coronavirus-i-sverige/

Folkhälsomyndigheten (2020e) Information till förskola, grundskola och gymnasier om covid-19. https://www.folkhalsomyndigheten.se/smittskydd-beredskap/ utbrott/aktuella-utbrott/covid-19/verksamheter/information-till-skola-ochforskola-om-den-nya-sjukdomen-covid-19/ 
Francia, G. (2018) L'enseignement en Suède: D'une école pour tous à une école pour chacun. En F. Baluteau., V. Dupriez., \& M. Verhoeven (Eds.), Entre tronc commun et filières, quelle école commune ? Etude comparative (pp.203-236). Thélème (Académia-L'Harmattan).

Fundación BBVA (2016). Recuperación económica y bienestar social. La confianza en las instituciones públicas perdida durante la crisis apenas se ha recuperado, pese a la mejora económica. Esenciales, 11. https://www.fbbva.es/wp-content/ uploads/2017/07/FBBVA_Esenciales_11_tcm269-621602.pdf

Fundación Family Watch (2020a). Informe 2020-1 Encuesta situación de las Familias durante el Coronavirus - Covid19. https://thefamilywatch.org/2020/10/16/ encuesta-situacion-de-las-familias-durante-el-coronavirus-covid19-2/

Fundación Family Watch (2020b). Informe 2020-1. $2^{\text {a }}$ Encuesta Covid-19: Las familias y la $\leq \leq$ Nueva Normalidad $>>$. https://thefamilywatch.org/2020/10/16/encuestasituacion-de-las-familias-durante-el-coronavirus-covid19-2/

Gobierno de España (2020). Guía de facilitación de acceso a las medidas. https://www. mscbs.gob.es/ssi/covid19/ccaa/home.htm

Grant, C., \& Zwier, E. (2017). Intersectionality and Education. Oxford Bibliographies. https://www.oxfordbibliographies.com/view/document/obo-9780199756810/ obo-9780199756810-0188.xml

Hagberg T., Jonung L., Kiander, J., \& Vartia P. (2006). Den ekonomiska krisen i Finland och Sverige. Uppgången, fallet och återhämtningen 1985-2000. [La crisis económica en Finlandia y Suecia. Ascenso, caída y recuperación] En J. Aunesluoma \& S. Fellman (Eds), Från olika till jämlika: Finlands och Sveriges ekonomier på 190o-talet, [De diferentes a iguales: Las economías de Finlandia en el 1900]. Helsingfors. http://www.internetional.se/jonungfinlando4.pdf

Hesselius, P. (2011). De svenska sjuk- och arbetslöshetförsäkringar- är de unika? Son únicos los sistemas de cobertura de enfermedad y de seguro contra la desocupación] TIMBRO [VÄLFÄRD \&REFORM ] [Bienestar \& Refor- ma] http://www.timbro. se/bokhandel/pdf/9175668062.pdf

Instituto Nacional de Estadística (INE). (2020a). Encuesta de Población Activa. https:// www.ine.es/up/rTBuNOB2i5

Instituto Nacional de Estadística (INE). (2020b). Tasas de empleo. https://www.ine. es/infografias/tasasepa/desktop/tasas.html?t=1\&lang=es

Instituto de la Mujer (2020). La perspectiva de género, esencial a la respuesta a la COVID-19. Ministerio de Igualdad.

Jämlikhetsmyndigheten (2020), CORONAEPIDEMIN I ETT JÄMSTÄLDHETSPERSPETIV. https://www.jamstalldhetsmyndigheten.se/aktuellt/coronapandemin-2

Jämställdhetsmyndigheten (2021) Covid-19 och Våldsutsatthet . Rapport 8. Slutrapport av uppdrag A202O-O1OO1. https://www.jamstalldhetsmyndigheten.se/covid-19och-valdsutsatthet-20218 
Johns Hopkins Coronavirus Resource Center (2021). Maps and Trends. Mortality Analyses. https://coronavirus.jhu.edu/data/mortality

Läkartidningen (2020) Sjukhusläkarna i Stockholm kräver munskydd i butiker. https:// lakartidningen.se/aktuellt/nyheter/2020/11/sjukhuslakarna-i-stockholm-kravermunskydd-i-butiker/_

Landsorganisationen i Sverige (2010). Arbetsrätten med en borgerlig regering. [E] derecho de trabajo cuando el gobierno http://www.lo.se/home/lo/res.nsf/ vres/lo_1366026597536_ar- betsratten_rattsskyddet_pdf/\$file/Arbetsratten_ Rattsskyddet.pdf

Lorente-Acosta, M. (2020). Violencia de género en tiempos de pandemia y confinamiento. Revista Española de Medicina General, 46(3), 139-145. DOI: 10.1016/j. reml.2020.05.005

Lundahl, L., Arreman, I. E., Holm, A. S., \& Lundström U. (2013). Educational marketization The Swedish way. Education Inquiry, 4, 3, 497-517.

Moreno, L. (2001). La «vía media» española del modelo de bienestar mediterráneo. Papers, 63/64, 67-82. http://dx.doi.org/10.5565/rev/papers/v63no.1207

Moreno, L. (2002). Bienestar mediterráneo y «supermujeres». Revista Española De Sociología, (2). https://recyt.fecyt.es/index.php/res/article/view/64862

Moreno, L., y Mari-Klose, P. (2016). Bienestar mediterráneo: Trayectorias y retos de un régimen en transición. En E. del Pino y M. J., Rubio (eds.), Los Estados de Bienestar en la encrucijada. Políticas Sociales en Perspectiva comparada (pp.139160). Tecnos.

Navarro, V. (2006). El subdesarrollo social de España. Causas y consecuencias. Angrama.

Newtral (2020). Newtral Hemeroteca: Cuando el Gobierno sí hablaba del comité de expertos. https://www.newtral.es/newtral-hemeroteca-gobierno-comiteexpertos/20200730/

Nordisk Information för kunskap om kön. (2021) Jämställdhetseffekter av covid-19. Kunskap och initiativ i Norden. NIKKpå uppdrag av Nordiska ministerrådet. file:///Users/guefra/Desktop/FORSKNING/Mina\%20artiklar\%202021/ Genus\%20covid\%20Cristina\%20G\%20Ana/Jamstalldhetseffekter-av-covid-19Kunskap-och-initiativ-i-Norden_1.pdf

OCDE (2020). Panorama de la Educación. Indicadores de la OCDE 202O. Ministerio de Educación y Formación Profesional, Gobierno de España.

OECD/European Union (2020), Health at a Glance: Europe 2020: State of Health in the EU Cycle. OECD Publishing. https://doi.org/10.1787/82129230-en

ONU-MUJERES (2020) La pandemia en la sombra: violencia contra las mujeres durante el confinamiento. https://www.unwomen.org/es/news/in-focus/in-focus-genderequality-in-covid-19-response/violence-against-women-during-covid-19 
Organización Mundial de la Salud (OMS) (2009). Subsanar las desigualdades de la salud. Comisión sobre Determinantes sociales de la Salud. https://www.who.int/ social_determinants/thecommission/finalreport/es/

Peterson, E. (2019). Género y Estado de bienestar en las políticas españolas / Gender and Welfare State in Spanish Policies. Asparkía. Investigació Feminista, (20), 3557. https://www.e-revistes.uji.es/index.php/asparkia/article/view/437

Picatoste, X. (2018). Efectos de las políticas de austeridad en el empleo juvenil. Atlantic Review of Economics (ARoEc), 1 (3), 1-20. http://hdl.handle.net/10419/191972

PNUD (2020). Dashboards on the Gender Inequality and the COVID-19 crisis with a Human Development perspective. http:/hdr.undp.org/sites/default/files/ gendercovid_final.xlsx

PSOE/Unidas-Podemos (2019). Coalición progresista. Un nuevo acuerdo para España. https://www.psoe.es/actualidad/documentos-de-interes/acuerdo-de-coalicionprogresista-entre-psoe-y-unidas-podemos/

Regeringengskansliet (2020) Strategi med anledning av det nya coronaviruset. https://www.regeringen.se/regeringens-politik/regeringensarbete-medcoronapandemin/strategi-med-anledning-av-det-nya

RENAVE (2020). Informe $n^{o}$ 54. Situación de COVID-19 en España. Casos diagnosticados a partir 10 de mayo Informe COVID-19.25 de noviembre de 2020. https://www.isciii.es/QueHacemos/Servicios/VigilanciaSaludPublicaRENAVE/ EnfermedadesTransmisibles/Paginas/InformesCOVID-19.aspx

Ruíz-Cantero, M. T. (en prensa). Las estadísticas sanitarias y la invisibilidad por sexo y de género durante la epidemia de COVID-19. Gaceta Sanitaria Doi: https://doi. org/10.1016/j.gaceta.2020.04.008

Save the Children (Rädda Barnen2020). Milleniebarnen. En Studie om ekonomisk uttsathet bland barn under hela utväxten. https://resourcecentre.savethechildren. net/node/18437/pdf/millenniebarnen_raddabarnen_201105.pdf

Save the Children (2021). Aniversario Covid-19: ¿Qué nos cuentan las familias?. Unidad de Calidad y Evidencias.

SCB (2020) Fler grundskollärare än någonsin - men lägre andel med examen. Senast uppdaterad: 2020-08-25https://www.scb.se/hitta-statistik/artiklar/2020/flergrundskollarare-an-nagonsin--men-farre-med-examen/

Socialstyrelsen (2020), Sammanfattande statistik och utveckling över tid om covid-19. https://www.socialstyrelsen.se/statistik-och-data/statistik/statistik-omcovid-19/sammanfattande-statistik-over-tid/

SOU (2018). Styra och leda med tillit Forskning och praktik Louise Bringselius (red.) Statens Offentliga Utredningar. https://www.regeringen.se/rattsliga-dokument/ statens-offentliga-utredningar/2018/o6/sou-201838/ 
Sveriges Riksbank (1999). Den svenska finansvärlden [El mundo financiero sueco] http://www.riksbank.se/Upload/Dokument_riksbank/Kat_publicerat/ Rapporter/finmar_98_sv.pdf.

UNESCO (2020). COVID-19 Educational Disruption and Response. https://en.unesco. org/covid19/educationresponse

Vlachos, J., Hertegard, E. \& Svaleryd, H. (2021). School closures and SARS-CoV-2. Evidence from Sweden'spartial school closure. COVID-19 SARS-CoV-2 preprints from medRxiv and bioRxiv. doi: https://doi.org/10.1101/2020.10.13.20211359

WHO (2020). Coronavirus Disease (COVID-19) Dashboard. https://globalhealth5050. org/the-sex-gender-and-covid-19-project/the-data-tracker/?explore=country

YoNoRenuncio (2021). Encuesta \#YoNoRenuncio. Club de las MalasMadres. https:// yonorenuncio.com/una-de-cada-cuatro-mujeres-ha-renunciado-a-todo-o-partede-su-trabajo-para-cuidar-segun-la-encuesta-yonorenuncio/ 